Effects of hypoxia of 10-45 seconds duration on energy metabolism in the cerebral cortex of unanesthetized and anesthetized rats.

Quistorff, Bjørn; Norberg, Karin; K. Siesjö, Bo

Published in:

Acta Physiol Scand.

Publication date:

1975

Document version

Publisher's PDF, also known as Version of record

Citation for published version (APA):

Quistorff, B., Norberg, K., \& K. Siesjö, B. (1975). Effects of hypoxia of 10-45 seconds duration on energy metabolism in the cerebral cortex of unanesthetized and anesthetized rats. Acta Physiol Scand., 301-310. 
Acta physiol. scand. 1975. 95. 301-310

From the Brain Research Laboratory, E-Blocket, University Hospital, Lund; and Department of Biochemistry A, University of Copenhagen, Denmark

\title{
Effects of Hypoxia of 10-45 Seconds Duration on Energy Metabolism in the Cerebral Cortex of Unanesthetized and Anesthetized Rats
}

\author{
By
}

KARIN NORBERG, BJÖrN QUISTORFF and Bo K. SiesJö

Received 18 April 1975

\section{Abstract}

NorberG, K., B. QUISTORFF and B. K. SiesJö. Effects of hypoxia of 10-45 seconds duration on energy metabolism in the cerebral cortex of unanesthetized and anesthetized rats. Acta physiol. scand. 1975. 95. 301-310.

Glycolytic and citric acid cycle intermediates, as well as organic phosphates, were measured in the cerebral cortex of unanesthetized rats following arterial hypoxia (administration of $6-8 \% \mathrm{O}_{2}$ ) of 10 and 20 s duration. There were decreases in glucose-6-phosphate and fructose-6-phosphate, and increases in fructose-1,6diphosphate, dihydroxyacetone phosphate and 3-phosphoglycerate, even before pyruvate accumulated. Since measurements of the lactate concentration showed that there was an increased glycolytic rate, the results demonstrate that phosphofructokinase was activated. The glycolytic changes were accompanied by, and probably due to, minor changes in phosphocreatine, ATP, ADP and AMP. Experiments of anesthetized animals showed that hypoxia for $45 \mathrm{~s}$ was accompanied by signs of phosphofructokinase activation, even if tissue $\mathrm{PCO}_{2}$ was kept constant. It is concluded that, irrespective of the tissue $\mathrm{CO}_{2}$ tension, hypoxia is accompanied by activation of phosphofructokinase which, at least initially, is responsible for the increased glycolytic rate.

Recent results (Duffy et al. 1972, Bachelard et al. 1974, Norberg and Siesjö 1975a and b) have provided new information on the cerebral metabolic changes that occur when animals are exposed to atmospheres containing low concentrations of oxygen ("hypoxic hypoxia"). The following tentative conclusions were drawn: Soon after the induction of hypoxia, there is acceleration of glycolytic rate with accumulation of lactate and pyruvate, and increase in the lactate/pyruvate ratio. As a part of a generalized oxidation/reduction change there is also an increase in the malate/oxaloacetate ratio with a fall in oxaloacetate (OAA) concentration. The latter induces a shift in the aspartate aminotransferase equilibrium, resulting in an initial reduction in $\alpha$-ketoglutarate $(\alpha-K G)$ level and a sustained reduction in aspartate. When hypoxia is prolonged, the elevated pyruvate concentration induces a shift in the alanine aminotransferase reaction towards alanine formation, as well as an increased rate of 
$\mathrm{CO}_{2}$ fixation. As a result, there is an increased alanine concentration and an increase in the pool size of tricarboxylic acid cycle (TCA) intermediates.

There have been some difficulties in defining the regulatory, enzymatic reaction that is responsible for the accelerated glycolysis. Two previous studies were partly devoted to this problem (Duffy et al. 1972, Bachelard et al. 1974) but in none could evidence be obtained for an activation of phosphofructokinase (PFK), the enzyme which is considered to exert the main regulatory control of glycolytic rate (Lowry and Passonneau 1964, 1966). The results of both groups of workers were consistent with the idea that, in hypoxia, pyruvate kinase may be regulatory. However, by shortening the period of hypoxia to $45 \mathrm{~s}$, or $1 \mathrm{~min}$ and $45 \mathrm{~s}$, and by allowing the $\mathrm{P}_{\mathrm{CO}_{2}}$ to fall spontaneously, we could show that an activation of PFK activity is involved in triggering an increased glycolytic rate (Norberg and Siesjö 1975 a). Our tentative explanation for the difference in results between that study and the previous one (Bachelard et al. 1974) was as follows. Soon after the induction of hypoxia there is an imbalance between production and utilization of ATP. The consequences of this imbalance, i.e. a moderate increase in ADP (and $\mathbf{P}_{\mathrm{i}}$ ), and a decrease in phosphocreatine, lead to PFK activation and increased glycolysis. However, the activity of PFK is later decreased, relative to the activities of hexokinase and of pyruvate kinase, and this "inactivation" of PFK is accelerated by the development of tissue acidosis.

Before a completely satisfactory explanation can be given of the glycolytic events in hypoxia some further information is required. Firstly, previous results were obtained in nitrous oxide anesthesia and, since anaesthesia may blunt the tissue response to hypoxia, it would be desirable to study unanesthetized animals. Secondly, no information is at hand about metabolic changes occurring during the first $45 \mathrm{~s}$ period of hypoxia. Thus, tissue analyses performed at the very induction of tissue hypoxia might reveal larger changes in labile phosphates than are observed after $45 \mathrm{~s}$ in anesthetized animals. Such information is also essential for establishing that the increased pyruvate and lactate concentrations are consequences of increased glycolysis, and not just due to reduced pyruvate oxidation. Thus, if it could be shown that PFK is activated before pyruvate and lactate have accumulated, this problem would be solved. Thirdly, when the arterial $\mathrm{P}_{\mathrm{CO}_{2}}$ is allowed to fall during the hypoxia there is in all probability an alkaline shift of intracellular $\mathrm{pH}$ during the first minutes (Norberg and Siesjö 1975 a). Since alkalosis is believed to stimulate glycolysis (Delcher and Shipp 1966) it becomes difficult to decide whether or not it contributes to PFK activation. Accordingly, it would be desirable to establish that PFK activation occurs at constant $\mathrm{CO}_{2}$ tension in the tissue.

The present experiments were designed to provide information on the above points. By using a "freeze clamping" technique (Quistorff 1975) it was possible to obtain cerebral cortical tissue for analysis from unanesthetized animals, and to study hypoxia of only 10 or $20 \mathrm{sec}$ duration. Activation of glycolysis at an unchanged tissue $\mathrm{CO}_{2}$ tension was studied in anesthetized animals following a hypoxic period of $45 \mathrm{sec}$.

\section{Methods}

The experiments were performed on male Wistar rats that had free access to water and rat pellets until studied. There were two main series of animals-unanesthetized and anesthetized-and these will be described separately. 
Unanesthetized animals

In the unanesthetized animals, weighing $200-220 \mathrm{~g}$, a preliminary operation was performed under $2 \%$ halothane anesthesia, and a tail artery catheter was inserted. After 1-2 hrs of recovery the rats were allowed to creep into the cylinder of the freeze-clamping apparatus (see Quistorff 1975), and were kept there in a restrained position for 10-20 min. During this period of adaptation the cylinder was flushed with room air, and measurements were made of blood pressure, rectal temperature and of arterial $\mathrm{PO}_{2}, \mathrm{P}_{\mathrm{CO}_{2}}$ and $\mathrm{pH}$. Hypoxia was then induced for either 10 or $20 \mathrm{~s}$ by rapid switching to a hypoxic gas mixture containing 6-8\% $\mathrm{O}_{2}$. In preliminary experiments, serial samples were drawn from the artery for determining the time course of the changes in arterial gas tensions during the induction of hypoxia.

The controls were freeze-clamped at the end of the adaptation period, and the hypoxic animals at the end of the 10 and $20 \mathrm{~s}$ periods of hypoxia. At the time of freeze-clamping, an arterial blood sample was drawn. The performance of the apparatus is such that the part of the rat positioned in the "biopsy region" of the cylinder is cut free and freeze-clamped between precooled aluminium blocks in about $0.1 \mathrm{~s}$. (For details of sampling procedure, see Quistorff 1975.) The freeze-clamped slice, which contained the mid-part of the brain, was immersed in liquid nitrogen and later stored at $-80^{\circ} \mathrm{C}$. Using a buzz saw at $-30^{\circ} \mathrm{C}$, a 1-2 mm thick section was then cut off from the surface of the brain section that had been brought in contact with one of the freeze-clamping blocks. Cerebral cortical tissue from this thin section was used for analyses.

\section{Anesthetized animals}

In the anesthetized series of animals (hypoxic and control animals, the latter maintained at an arterial $\mathrm{P}_{2}$ of $>100 \mathrm{~mm} \mathrm{Hg}$ ), the techniques used were similar to those described previously (Norberg and Siesjö 1975 a) and the reader is referred to that publication for details. The main features were as follows. Anesthesia was induced with $2-3 \%$ halothane and the animals were tracheotomized, immobilized with tubocurarine chloride and connected to a respirator. At the time of tracheotomy the halothane anesthesia was discontinued and the animals were maintained on $70 \% \mathrm{~N}_{2} \mathrm{O}$ and $30 \% \mathrm{O}_{2}$ until hypoxia was induced. An arterial catheter was inserted to allow sampling of arterial blood and measurement of blood pressure. The body temperature, as measured in the rectum, was kept close to $37^{\circ} \mathrm{C}$. The skin over the head was incised to accommodate a plastic funnel for subsequent freezing of the tissue in situ. At the induction of hypoxia, the oxygen concentration of the inspired air was decreased so as to give a (final) arterial $\mathrm{PO}_{2}$ of about $25 \mathrm{~mm} \mathrm{Hg}$, keeping the $\mathrm{N}_{2} \mathrm{O}$ concentration constant. The gas mixture administered contained sufficient carbon dioxide to increase arterial $\mathrm{PCO}_{2}$ by $2-4 \mathrm{~mm} \mathrm{Hg}$ during the hypoxia. After $45 \mathrm{~s}$ of hypoxia, the tissue was frozen in situ by pouring liquid nitrogen into the funnel. The frozen tissue was kept at $-80^{\circ} \mathrm{C}$. Cortical tissue was then cut out, weighed and extracted at $-22^{\circ} \mathrm{C}$.

\section{Analytical techniques}

$\mathrm{PO}_{2}$ and $\mathrm{PCO}_{2}$ in arterial blood were measured at $37^{\circ} \mathrm{C}$ with microelectrodes. Cortical tissue was dissected, weighed and extracted with $\mathrm{HCl}$-methanol at $-22^{\circ} \mathrm{C}$. The following metabolites were analysed (in some brains only a selected number was studied): phosphocreatine (PCr), creatine, ATP, ADP, AMP, glycogen, glucose, glucose-6-phosphate (G-6-P), fructose-6-phosphate (F-6-P), fructose-1,6-diphosphate (FDP), dihydroxyacetone phosphate (DHAP), 3-phosphoglycerate (3-PG), pyruvate, lactate, citrate, $\alpha$-ketoglutarate $(\alpha-\mathrm{KG})$, succinate, malate, glutamate, aspartate and $\mathrm{NH}_{4}^{+}$. The basic methods were those described by Lowry and Passonneau (1972) and analytical conditions have been given in previous communications (for references, see Folbergrová et al. 1974). The oxaloacetate concentrations were calculated from the aspartate aminotransferase reaction, using an equilibrium constant of 6.7 (Krebs 1957).

Statistical differences were calculated using Aspin-Welch's test or the nonparametric Mann-Whitney U-test, when the values within the group did not seem to follow a normal distribution. The following symbols are used: ${ }^{*}=\mathrm{p}<0.05, * *=\mathrm{p}<0.01$ and $* * *=\mathrm{p}<0.001$.

\section{Results}

\section{Unanesthetized animals}

These animals were provided with tail artery catheters, and cortical tissue was obtained for analysis by means of "freeze clamping", following exposure to about 8 and $6 \% \mathrm{O}_{2}$, respectively. Originally, the gas with the lower concentration (6\%) was administered to one group 


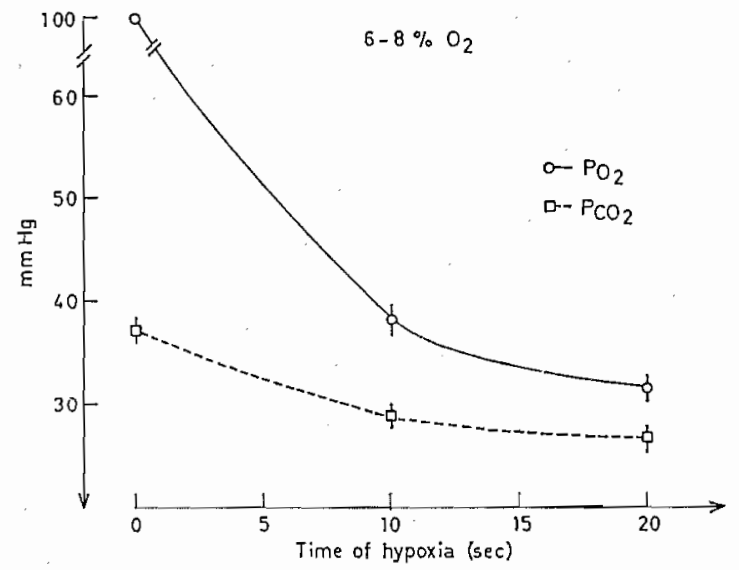

Fig. 1. Time course of changes in arterial $\mathrm{PO}_{3}$ and $\mathrm{PCO}_{2}$ during administration of $6-8 \% \quad \mathrm{O}_{2}$ to unanesthetized rats. The values are means \pm S.E.M.

of animals $(\mathrm{n}=4)$, studied after $10 \mathrm{~s}$ of hypoxia, in an attempt to maintain $\mathrm{Pa}_{\mathrm{O}_{2}}$ constant at 10 and $20 \mathrm{~s}$ of hypoxia. However, the $\mathrm{Pa}_{\mathrm{O}_{2}}$ obtained was not significantly different from that observed with $8 \% \mathrm{O}_{2}$. For this reason, all values obtained at $10 \mathrm{~s}$ were pooled. Since also the two control groups were pooled, there were 9 control animals, 10 hypoxic animals studied at $10 \mathrm{~s}$, and another 6 studied at $20 \mathrm{~s}$. The mean $\mathbf{P}_{\mathrm{O}_{2}}$ and $\mathrm{P}_{\mathrm{CO}_{2}}$ values obtained are shown in Fig. 1. At 10 and $20 \mathrm{~s}$, the mean arterial $\mathrm{P}_{\mathrm{O}_{3}}$ was 38.0 and $31.5 \mathrm{~mm} \mathrm{Hg}$, and arterial $\mathrm{P}_{\mathrm{CO}_{2}}$ was reduced by $8-10 \mathrm{~mm} \mathrm{Hg}$.

Fig. 2 shows the pattern of changes in glycolytic and citric acid cycle intermediates at 10 and $20 \mathrm{~s}$ of hypoxia as compared to the control values, the absolute values of which are given at the bottom. It should be noted that the control values obtained in unanesthetized animals after freeze-clamping were very close to those obtained with nitrous oxide anesthesia and surface freezing through the bone (see Norberg and Siesjö $1975 \mathrm{a}$, and b, and below). Although the changes observed at $20 \mathrm{~s}$ were somewhat more marked than those seen at $10 \mathrm{~s}$, the pattern was consistent. There were no changes in glycogen but significant reductions in glucose content. However, this reduction should be interpreted with caution since, in any given animal, the glucose content in the tissue must depend on the blood glucose concentra-

TABLE I. Cerebral cortex concentrations of ATP, ADP, AMP, $\mathrm{PCr}, \mathrm{Cr}$ and $\mathrm{NH}_{4}^{+}$in unanesthetized animals following administration of gases with low oxygen content $\left(6-8 \% \mathrm{O}_{2}\right)$ for 10 or $20 \mathrm{~s}$. The values, expressed in $\mu \mathrm{mol} / \mathrm{g}$ of wet tissue; are means \pm S.E.M.

\begin{tabular}{|c|c|c|c|c|c|c|c|}
\hline $\begin{array}{l}\text { Time of } \\
\text { hypoxia }\end{array}$ & $\mathrm{n}$ & ATP & ADP & AMP & $\mathrm{PCr}$ & $\mathrm{Cr}$ & $\mathrm{NH}_{4}^{+}$ \\
\hline 0 & 9 & $\begin{array}{r}2.75 \\
+0.04\end{array}$ & $\begin{array}{r}0.399 \\
+0.012\end{array}$ & $\begin{array}{r}0.060 \\
\pm 0.005\end{array}$ & $\begin{array}{r}3.17 \\
+0.11\end{array}$ & $\begin{array}{r}6.84 \\
+0.16\end{array}$ & $\begin{array}{r}0.202 \\
\pm 0.011\end{array}$ \\
\hline $10 \mathrm{~s}$ & 10 & $\begin{array}{r}2.67 \\
\pm 0.05\end{array}$ & $\begin{array}{r}0.421 \\
\pm 0.015\end{array}$ & $\begin{array}{r}0.068 \\
+0.007\end{array}$ & $\begin{array}{l}2.79 * * \\
\pm 0.07\end{array}$ & $\begin{array}{r}7.28 \\
\pm 0.26\end{array}$ & $\begin{array}{r}0.196 \\
\pm \mathbf{0 . 0 2 2}\end{array}$ \\
\hline $20 \mathrm{~s}$ & 7 & $\begin{aligned} & 2.61 * \\
\pm & 0.03\end{aligned}$ & $\begin{aligned} & 0.475^{* *} \\
\pm & 0.018\end{aligned}$ & $\begin{aligned} & 0.111^{* *} \\
\pm & 0.012\end{aligned}$ & $\begin{array}{l}2.15^{* * *} \\
\pm 0.09\end{array}$ & $\begin{aligned} & 8.26^{* * *} \\
\pm & 0.22\end{aligned}$ & $\begin{array}{r}0.272 * \\
\pm 0.027\end{array}$ \\
\hline
\end{tabular}


Fig. 2. Influence of hypoxia (administration of $6-8 \% \mathrm{O}_{2}$ ) of 10 and $20 \mathrm{~s}$ duration upon cerebral cortex concentration of glycolytic and citric acid cycle metabolites. Values are means + S.E.M. in per cent of the control values that are given at the bottom. Filled symbols denote values significantly different from the controls $(p<0.05)$. Abbreviations used: $\mathrm{Gly}=$ glycogen, Glu=glucose, G-6-P=glucose-6-phosphate, $F-6-P=$ fructose6-phosphate, FDP $=$ fructose- 1,6 diphosphate, DHAP = dihydroxyacetone phosphate, 3-PG $=3$-phosphoglycerate, Pyr= pyruvate, Citr $=$ citrate,$\quad \alpha-K G=\alpha$-ketoglutarate, $\mathrm{Mal}=$ malate, $\mathrm{OAA}=$ oxaloacetate.

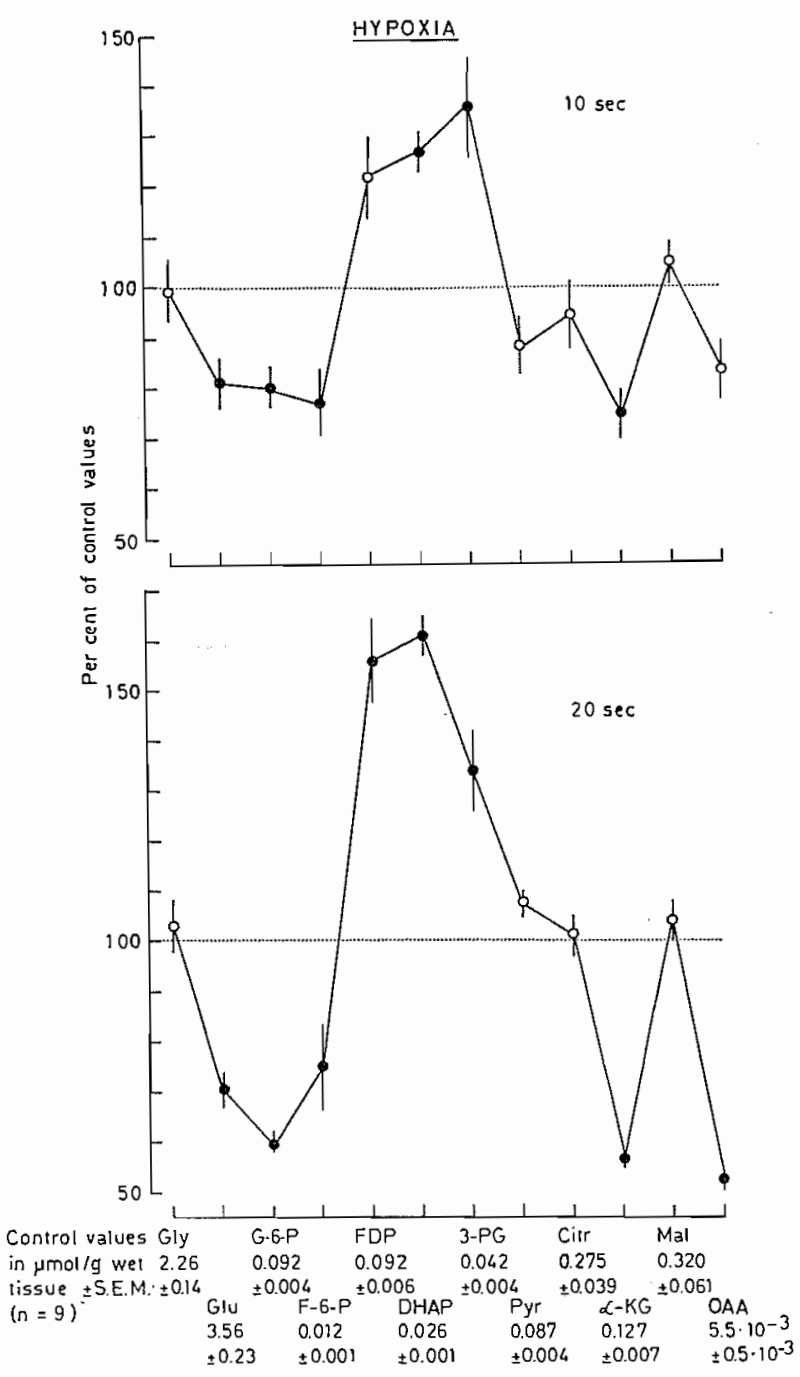

tion. The latter was measured in 4 control animals and in 4 animals exposed to $6 \% \mathrm{O}_{2}$ for $10 \mathrm{~s}$. The blood glucose concentrations in these groups were $10.2 \pm 0.3$ and $9.5 \pm 0.4 \mu \mathrm{mol} / \mathrm{g}$, respectively, and the corresponding tissue to blood glucose concentration ratios were $0.33 \pm$ 0.04 and $0.32 \pm 0.03$, respectively. Thus, there were small, if any, changes in the ratios.

In the hypoxic animals, there were decreases in G-6-P, F-6-P, $\alpha-\mathrm{KG}$ and (calculated) OAA, and increases in FDP, DHAP and 3-PG. These results are entirely consistent with those obtained previously (Norberg and Siesjö $1975 \mathrm{a}$ and $\mathrm{b}$ ) and demonstrate that, in unanesthetized animals, activation of PFK occurs already $10 \mathrm{~s}$ following induction of hypoxia (see Discussion).

Although there were signs of an activation of PFK at $10 \mathrm{~s}$ of hypoxia, there was neither an increase in tissue lactate content at that time, nor significant elevations of lactate/pyruvate 


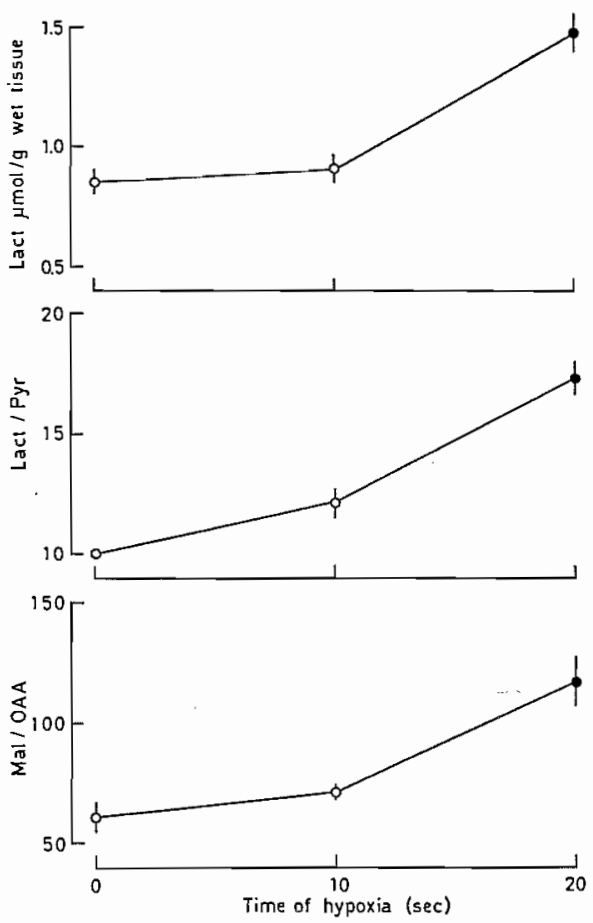

Fig. 3. Influence of hypoxia (administration of 6$8 \% \mathrm{O}_{2}$ ) on cerebral cortex concentrations of lactate, and on calculated lactate/pyruvate and malate/ oxaloacetate ratios in unanesthetized animals. Means \pm S.E.M. Filled symbols denote values significantly different from the controls $(p<0.05)$.

and malate/oxaloacetate ratios (Fig. 3). At $20 \mathrm{~s}$, the lactate content and the ratios for the redox couples were significantly increased.

Table I illustrates the tissue concentrations of ATP, ADP, AMP, PCr, creatine and $\mathrm{NH}_{4}^{+}$. It should be noted that, although "freezeclamping" introduces a very short delay between in terruption of cerebral circulation and freezing of the tissue, the values for organic phosphates were less "optimal" than those obtained with surface freezing without previous interruption of circulation (see Norberg and Siesjö $1975 \mathrm{a}$ and below). Thus, PCr was about 1.5 $\mu \mathrm{mol} / \mathrm{g}$ lower, ADP about $0.1 \mu \mathrm{mol} / \mathrm{g}$ higher, and AMP about twice as high as with surface freezing. Although these differences indicate that there were some autolytic changes with freeze-clamping, the values are sufficiently close to the "normal" to allow comparison between control and hypoxic brains. Thus, at $20 \mathrm{~s}$, there was a highly significant decrease in PCr and increase in Cr, there were significant increases in ADP and AMP, and a small reduction in ATP. The data obtained at $10 \mathrm{~s}$ indicated that smaller, but similar changes had occurred but only the decrease in $\mathrm{PCr}$ was statistically significant. The $\mathrm{NH}^{+}$concentration was normal at $10 \mathrm{~s}$ of hypoxia but significantly increased at $20 \mathrm{~s}$. The data allow a discussion of activation of glycolysis in terms of changes in concentration of glycolytic modulators (see Discussion).

\section{Anesthetized animals}

In the hypoxic animals, the arterial $\mathrm{P}_{\mathrm{O}_{2}}$ was reduced to $26.3 \pm 0.6 \mathrm{~mm} \mathrm{Hg}$ as compared to $144 \pm 6 \mathrm{~mm} \mathrm{Hg}$ in the controls. By addition of $\mathrm{CO}_{2}$ to the gas mixture administered to the 
Fig. 4. Influence of hypoxia (reduction in arterial $\mathrm{P}_{\mathrm{O}_{3}}$ to 26-27 $\mathrm{mm} \mathrm{Hg}$ ) upon cerebral cortex concentrations of glycolytic and citric acid cycle intermediates in rats anesthetized with nitrous oxide $(70 \%)$. The values obtained in normocapnic animals $\left(\mathrm{PacO}_{2}\right.$ $41 \mathrm{~mm} \mathrm{Hg}$ ) were compared to those previously obtained in hypocapnic animals (Norberg and Siesjö $1975 \mathrm{a}$ and $b$ ). The values are means \pm S.E.M. in per cent of controls, that are given at the bottom. Filled symbols denote values significantly different from the controls $(p<0.05)$. Succ $=$ succinate. For further abbreviations, see Fig. 2.

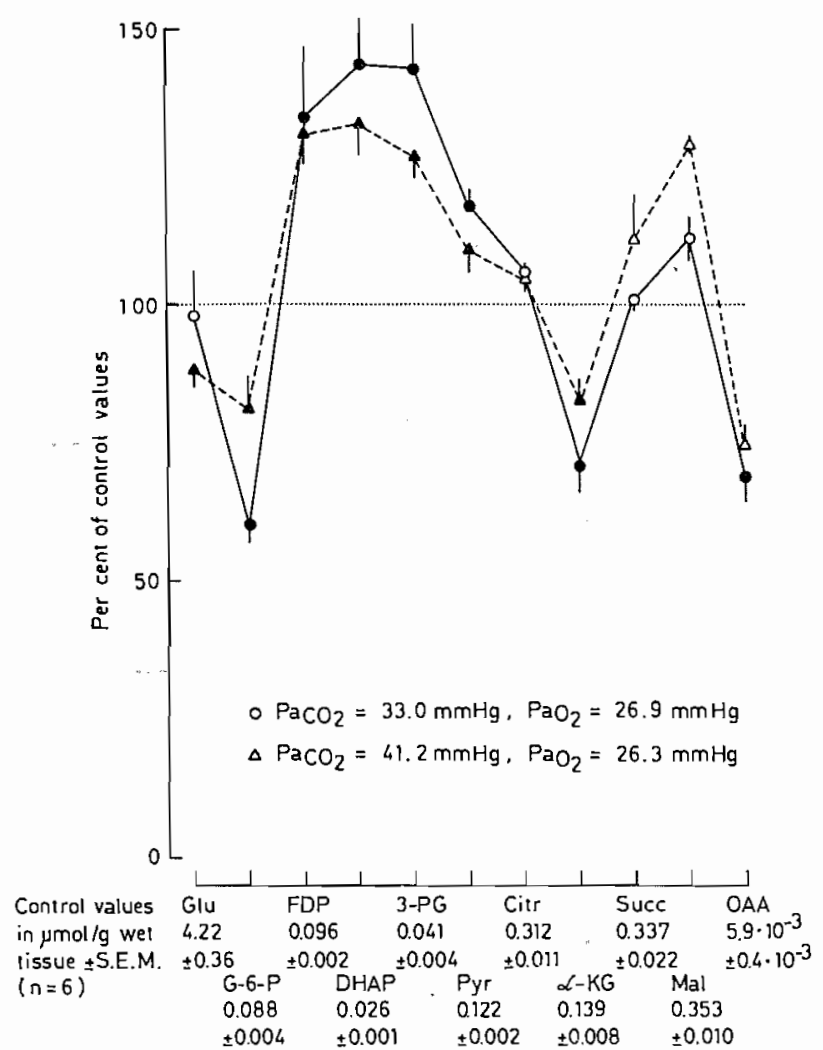

hypoxic animals the arterial $\mathrm{P}_{\mathrm{CO}_{3}}$ could be kept at $41.2 \pm 0.7 \mathrm{~mm} \mathrm{Hg}$, values that were slightly higher than those of the controls $(37.9 \pm 0.4 \mathrm{~mm} \mathrm{Hg})$. The difference ensured that tissue $\mathrm{P}_{\mathrm{CO}_{2}}$ was kept at, or just above, the normal value even if there was an increase in cerebral blood flow (see Bachelard et al. 1964).

Fig. 4 shows the changes observed in glycolytic and citric acid cycle metabolites in nor-

TABLE II. Influence of reduction in arterial $\mathrm{Po}_{2}$ to $26 \mathrm{~mm} \mathrm{Hg}$ on tissue metabolites in normocapnic rats, anesthetized with nitrous oxide. The duration of hypoxia was $45 \mathrm{~s}$. Values are means \pm S.E.M. ( $\mathrm{n}=6$ in both groups).

\begin{tabular}{lll}
\hline & Control & $\begin{array}{l}\text { Hypoxia } \\
\text { Normocapnia }\end{array}$ \\
\hline PCr & & $3.79 \pm 0.04^{* * *}$ \\
Cr & $4.35 \pm 0.06$ & $6.56 \pm 0.10^{* *}$ \\
ATP & $6.04 \pm 0.05$ & $2.96 \pm 0.05$ \\
ADP & $3.02 \pm 0.03$ & $0.304 \pm 0.005$ \\
AMP & $0.299 \pm 0.006$ & $0.030 \pm 0.001^{*}$ \\
Lactate & $0.026 \pm 0.001$ & $1.88 \pm 0.07^{* * *}$ \\
Lact/Pyr & $1.32 \pm 0.05$ & $14.1 \pm 0.3^{* * *}$ \\
Glutamate & $10.8 \pm 0.3$ & $13.8 \pm 0.1$ \\
Aspartate & $13.4 \pm 0.2$ & $3.59 \pm 0.13$ \\
Ma1/OAA & $3.85 \pm 0.11$ & $103 \pm 4^{* * *}$ \\
\hline
\end{tabular}


mocapnic animals (triangles) and compares them to the corresponding changes observed at an identical $\mathrm{P}_{\mathrm{O}_{3}}$ in animals that became hypocapnic during the $45 \mathrm{~s}$ period of hypoxia (circles, values taken from Norberg and Siesjö 1975 a). The values for F-6-P were exluded since they varied unduly in the normocapnic group. The results demonstrate that the pattern of changes observed in the normocapnic animals was very similar to that previously obtained in hypocapnic animals. Thus, activation of glycolysis at the PFK step seems to occur even if the tissue $\mathbf{P}_{\mathrm{CO}}$ is held constant (see Discussion).

Table II shows the organic phosphates, the lactate contents, the lactate/pyruvate ratios, as well as the glutamate and aspartate concentrations. From the latter, and from the $\alpha-\mathrm{KG}$ concentrations (see Fig. 4), it was possible to derive OAA concentrations and, thereby, the malate/OAA ratios (see Methods). There was a highly significant decrease in $\mathrm{PCr}$, and increase in creatine, and a small rise in AMP, but no significant change in ADP. The lactate/ pyruvate and malate/OAA ratios were significantly increased.

\section{Discussion}

Freezing techniques suitable for studying cerebral metabolic changes during short periods of hypoxia in unanesthetized animals include the "brain blower" developed by Veech et al. (1973), and the "freeze-clamping" method (Quistorff 1975). Data obtained on control animals in the present series indicate that the techniques are comparable. Thus, although Veech et al. (1973) reported somewhat higher values for PCr, the ADP concentration was also higher, and the AMP values were similar. However, both these techniques give values for organic phosphates that are somewhat less "optimal" than those obtained by the standard freezing technique of this laboratory (Pontén et al. 1973). Probably, these differences are due to the fact that, in freeze-blowing or freeze-clamping, the circulation is interrupted before freezing occurs, and even if the delay before freezing is only 1-2 s, minor autolytic changes seem to occur. As remarked, these changes are so small, though, that they should not in any way invalidate the conclusions drawn from the present study. It should also be noted that freeze-clamping does not seem to affect the concentrations of glycolytic or citric acid cycle intermediates.

The present results, which extend those previously published (Norberg and Siesjö 1975 a and $b$ ), provide answers to the questions raised in the introduction. The main results concern the activation of glycolysis, and the "initial" changes occurring in citric acid cycle intermediates and organic phosphates. The glycolytic changes observed can be interpreted according to the postulate of Krebs (1957) which states that when the flux through the pathway is increased, there should be a decrease in the concentration of the substrate of a regulatory enzyme. In the previous studies it was not possible to prove that the flux was increased in hypoxia, but the present results show that this must be the case. Between 10 and $20 \mathrm{~s}$ of hypoxia the total sum of glycolytic intermediates plus lactate increased with $0.57 \mu \mathrm{mol} / \mathrm{g}$ of which lactate formation accounted for $0.55 \mu \mathrm{mol} / \mathrm{g}$. The oxygen consumption of the cerebral cortex in Wistar rats is about $4.5 \mu \mathrm{mol} /(\mathrm{g} \cdot \mathrm{min}$ ) (Norberg and Siesjö 1974) which corresponds to a glucose consumption of about $0.8 \mu \mathrm{mol} /(\mathrm{g} \cdot \mathrm{min})$. Thus, since the normal production of pyruvate should be about $1.6 \mu \mathrm{mol} /(\mathrm{g} \cdot \mathrm{min})$, or about $0.25 \mu \mathrm{mol} / \mathrm{g}$ for a $10 \mathrm{~s}$ 
period, accumulation of $0.55 \mu \mathrm{mol} / \mathrm{g}$ of lactate between 10 and $20 \mathrm{~s}$ shows that glycolysis was accelerated. Therefore, the glycolytic rate must have been at least doubled. These arguments could be wrong if pyruvate were formed in large amounts via the alanine aminotransferase reaction or from citric acid cycle intermediates via a reversal of $\mathrm{CO}_{2}$ fixation reactions. However, this possibility can be excluded since hypoxia is accompanied by an increase in the alanine concentration, and by an increase in the sum of citric acid cycle intermediates (Norberg and Siesjö 1975 b). Thus, in view of these arguments, and of the fact that signs of PFK activation occurred before pyruvate had accumulated, it can be concluded that acceleration of glycolysis was present.

In view of the fact that glycolytic rate was increased, and that there were decreases in G-6-P and F-6-P, it can be concluded that PFK was activated. In the present unanesthetized animals, this occurred already $10 \mathrm{~s}$ after the induction of hypoxia when the pyruvate and lactate concentrations had not yet increased. In the previous study (Norberg and Siesjö 1975 a) there were very small changes in organic phosphates, and it was concluded that if activation of PFK is secondary to a perturbation of the energy state, the enzyme must respond to very small changes in $\mathrm{PCr}, \mathrm{ADP}$ and $\mathrm{P}_{i}$. The present experiments confirm this conclusion since only $\mathrm{PCr}$ and creatine were significantly altered at $10 \mathrm{~s}$.

The present results showed that changes in the concentrations of $\alpha-\mathrm{KG}$ and OAA develop pari passu with those of glycolytic intermediates. At 10 and $20 \mathrm{~s}$, malate was not significantly changed, and the increase in malate/OAA ratio was thus due to a fall in OAA concentration. The present findings give support to the previously proposed sequence of events during hypoxia (Duffy et al. 1972, Norberg and Siesjö $1975 \mathrm{a}$ and b). Thus, it seems probable that an increased malate/OAA ratio, by causing a relative reduction in OAA concentrations, is accompanied by a shift of the aspartate aminotransferase reaction towards glutamate formation, giving rise to reduction in the aspartate and $\alpha-K G$ levels. Secondarily, this decrease in $\alpha-\mathrm{KG}$ can, together with a subsequent increase in pyruvate, also explain that there is eventually a shift in the alanine aminotransferase reaction with a rise in alanine concentration.

As judged from the changes in PCr, ATP, ADP and AMP (Table I), the perturbation of the energy state of the tissue in the present unanesthetized animals was larger than that observed previously on animals anaesthetized with nitrous oxide (Norberg and Siesjö 1975 a). However, two facts indicate that this is not necessarily the effect of anesthesia. First, the present results pertain to only 10 and $20 \mathrm{~s}$ of hypoxia. There are results which suggest that the compensatory increase in cerebral blood flow (CBF) develops during the first $2 \mathrm{~min}$ (Borgström et al. 1975). Thus, there may be a relatively large initial derangement of cerebral energy state which is later diminished due to hyperemia. Second, in preliminary experiments on the application of the present freezing technique, it was found that semi-steady state hypoxia ( $\mathrm{Pa}_{\mathrm{O}_{2}}$ about $25 \mathrm{~mm} \mathrm{Hg}$ for $30 \mathrm{~min}$ ) was associated with a fall in $\mathrm{PCr}$, but no detectable changes in ATP, ADP or AMP. These results are in accordance with previous ones obtained in $\mathrm{N}_{2} \mathrm{O}$ anesthesia (Bachelard et al. 1974). In view of these facts, we tentatively conclude that anesthesia with $\mathrm{N}_{2} \mathrm{O}$ does not significantly influence the response of the tissue to hypoxia.

The experiments carried out on anesthetized animals to evaluate the effect of $\mathrm{CO}_{2}$ tension demonstrate that, at $45 \mathrm{~s}$, there are signs of activation of $\mathrm{PFK}$ even if tissue $\mathrm{P}_{\mathrm{CO}_{2}}$ is held 
constant. There is thus no principal difference in response between normocapnic and hypocapnic animals. In all probability, the pattern typical of PFK activation disappears more rapidly in normocapnic animals because the developing tissue acidosis retards the activity of PFK, relative to that of other regulatory enzymes.

This study was supported by grants from the Swedish Medical Research Council (Projects No 14X-263 and 14X-2179), from the Swedish Tercentenary Fund, from US PHS Grant No RO1 NSO 7838-5 from NIH, from the Swedish Board for Technical Development.

\section{References}

Bachelard, H. S., L. D. Lewis, U. PONtÉN and B. K. Siesjö, Mechanisms activating glycolysis in the brain in arterial hypoxia, J. Nelrochem. 1974. 22.395-401.

Borgström, L., H. JohANNSSON and B. K. SIEsJÖ, The relationship between arteriaI $\mathrm{P}_{\mathrm{O}_{z}}$ and cerebral blood flow in hypoxic hypoxia. Acta physiol. scand. 1975. 93. 423-432.

DELCHER, H. K. and J. C. SHIPP, Effect of $\mathrm{pH}_{3} \mathrm{pCO}_{2}$ and bicarbonate on metabolism of glucose by perfused rat heart. Biochim. biophys. Acta (Amst.), 1966. 121. 250-260.

Duffy, T. E., S. R. Nelson and O. H. LowRY, Cerebral carbohydrate metabolism during acute hypoxia and recovery. J. Neurochem. 1972. 19.959-977.

Folbergroví, J., B. LJungGren, K. Norberg and B. K. Siesjö, Influence of complete ischemia on glycolytic metabolites, citric acid cycle intermediates, and associated amino acids in the rat cerebral cortex. Brain Res. 1974. 80. 265-279.

KREBS, H. A., Equilibria in transamination systems. Biochem. J. 1953. 54. 82-86.

KREBs, H. A., Control of metabolic processes. Endeavour 1957. 16. 125-132.

Lowry, O. H. and J. V. Passonneau, The relationship between substrates and enzymes of glycolysis in brain. J. biol. Chem. 1964. 239. 31-42.

LOWRY, O. H. and J. V. PASSONNEAU, Kinetic evidence for multiple binding sites on phosphofructokinase. J. biol. Chem. 1966. 241. 2268-2279.

Lowry, O, H. and J. V. Passonneau, A Flexible System of Enzymatic Analysis. Academic Press, New York and London 1972.

NORBERG, K. and B. K. Siesjö, Metabolism of oxygen, glucose, lactate and pyruvate in the rat brain in situ. I. Neurochem. 1974. 22. 1127-1129.

Norberg, K. and B. K. Siesjö, Cerebral metabolism in hypoxic hypoxia. I. Pattern of activation of glycoJysis. Brain Res. 1975 a. $86.31-44$.

Norberg, K. and B. K. Siesıö, Cerebral metabolism in hypoxic hypoxia. II. Citric acid cycle intermediates and associated amino acids. Brain Res. 1975 b. 86. $45-54$.

Pontén, U., R. A. Ratcheson, L. G. Salford and B. K. Siesjö, Optimal freezing conditions for cerebral metabolites in rats. $J$. Neurochem. 1973. 21. 1127-1138.

QUistoRfF, B., Mechanical device for rapid removal and freezing of liver or brain tissue from unanaesthetized and nonparalyzed rats. Analyt. Biochem. 1975. In press.

Veech, R. L., R. L. HARris, D. Veloso and E. H. VeEch, Freeze-blowing: a new technique for the study of brain in vivo. $J$. Neurochem. 1973. 20, 183-188. 